\title{
AS AVALIAÇÕES ESCRITAS NO ENSINO DE CIÊNCIAS: QUE TAL REVERMOS NOSSA PRÁTICA DOCENTE?
}

Francisco José Figueiredo Coelho

Brasil

\section{INTRODUÇÃO}

Como vem sendo produzidas as avaliações escritas de ciências? Dentre as várias situações que me instigaram a responder a essa pergunta, desenvolvendo esta pequena reflexão, uma delas é o somatório constante de perguntas em sala de aula ${ }^{1}$ do tipo "Professor, isso vai cair na prova?", "Como você vai pedir isso na prova?" ou "Professor, e se eu esquecer isso na hora da prova?". Nos mais variados contextos e expressa de muitas formas, no fundo, correspondem a mesma problemática: a super estimação da avaliação. Outra situação muito comum é a utilização da avaliação escrita como mantedora de disciplina em sala de aula. Lembro-me muitas vezes quando meus professores utilizavam de um verdadeiro terrorismo homeopático (como metaforiza Luckesi). O mais engraçado é que isso continua a acontecer ainda hoje e parece que continuará a existir ainda por muito tempo. Em Luckesi, (1996:18), encontramos uma referência para esse fenômeno escolar:

"Os professores utilizam as provas como instrumentos de ameaça e tortura prévia dos alunos, protestando ser um elemento motivador da aprendizagem. Quando o professor sente que seu trabalho não está surtindo o efeito esperado, anuncia aos seus alunos: Estudem! Caso contrário, vocês podem se dar mal no dia da prova"

Esses são alguns dos motivos pelos quais me interessei em escrever um pouco sobre a avaliação escrita e a propor algumas formas de utilização dessa tecnologia no âmbito do ensino de ciências. A avaliação poderia e deveria ser planejada considerando grande parte do que os alunos foram capazes de aprender nas aulas, isto é, o conhecimento científico que construíram durante um certo período, juntamente com suas experiências pessoais. Trataríamos de uma valorização dos conhecimentos adquiridos pelos alunos, não fazendo da avaliação escrita apenas uma avaliação conceitual e notificadora do aprendizado, pois sabemos que, nem sempre, este tipo de avaliação "prova" o potencial intelectual científico das crianças (o que legitima ainda hoje para os pais e muitos professores a lenda de que uma boa nota numa prova escrita é sinônimo de um bom aluno). As demais habilidades do educando parecem ter sido esquecidas nas aulas de ciências e demais disciplinas escolares. Mas será que essa postura do professor diante das avaliações é algo recente? A resposta é não. E encontramos subsídios teóricos concretos para essa resposta à medida que retrocedemos na história da educação no país (e também no âmbito da educação global) baseados no ensino tradicional amplamente controlador, enciclopédico e notificador. Como uma provável conseqüência disso, Luckesi (1996) atenta para a posição dos pais diante às avaliações:

"A realidade é que os próprios pais estão voltados para a promoção, estão na expectativa das notas de seus filhos. O importante é que tenham notas para serem aprovados."

Essa afirmação é verdadeira e pode ser comprovada em grande parte das reuniões de pais (quando estes comparecem) que ocorrem nas escolas, com as famigeradas perguntas "Professor, a nota dele está

\footnotetext{
${ }^{1}$ Práticas referentes às minhas turmas e a de outros colegas professores de ciências físicas e biológicas.
} 
baixa?" ou mesmo "Ele tem ponto para passar na prova?". Isso identifica a ineficácia do papel pedagógico familiar que a maioria dos pais apresenta, mas que não vamos nos aprofundar nesse trabalho. Para Rubem Alves (2003:53), às escolas e aos pais pouco importa o prazer que o aluno possa ter, importando para estes somente o boletim.

Odila Mansur e Renato Moretto, em sua obra Aprender a ensinar, numa perspectiva construtivista do conhecimento, esclarecem que, quando se faz a crítica à ênfase dada a avaliação ou à prova, se faz crítica a ser esta algo "especial", "aterrorizante", como costumeiramente se dá. Eles reafirmam que haverá sempre necessidade de que os alunos produzam conhecimento e o expressem. Quando fazemos às críticas ao processo avaliativo escrito, estamos criticando mais o modo como essa avaliação é feita e o que exige dos estudantes para a sua realização (p.87). Isso pode denotar um distanciamento da avaliação como forma de avaliar através da escrita os conhecimentos gerais construídos pelo aluno. Nem sempre estas provas vão de encontro aos objetivos de uma avaliação escrita e, tampouco, permite a expressão da compreensão dos conceitos fundamentais através de sua aplicação em questões cotidianas. Isso nos permite diferenciar um conhecimento cientificamente elaborado ${ }^{2}$ de um conhecimento científico transposto didaticamente (Chevallard,1991:45). Por esse mesmo motivo é que talvez muitos estudantes do ensino fundamental obtenham notas inferiores a média obtida, pois acabam levando consigo conceitos científicos (apenas informativos) mais elaborados, sem mesmo compreender os fenômenos e mecanismos científicos básicos. Essa massa de conhecimentos científicos teóricos muitas vezes acaba desestimulando os alunos para o hábito de leitura. Será que esse tipo de educação científica deveria ser caracterizada como constituinte de um ensino básico? Será que os professores vem esquecendo-se do que venha a ser uma educação básica? Que tal revermos nossa prática docente e tentarmos compreender a verdadeira função de uma avaliação escolar e, mais precisamente, de uma avaliação expressa de forma escrita?

A crença de que apenas por meio de provas escritas é possível verificar o nível de desempenho do aluno em relação a determinado conteúdo e classificá-lo como aprovado ou reprovado, revela uma prática pedagógica seletiva já existente na pedagogia jesuítica do século XVII, e ainda está presente nas escolas. No entanto, a falta de clareza das questões propostas em provas e testes denuncia também sua má elaboração. $E$ isso, sem dúvida, é algo a mais com que o aluno tem que se preocupar; ou seja, entender o que o professor pretende com a questão formulada. (Caetano, p. 98). Muitos professores elaboram suas provas para "provar" os alunos e não para auxiliá-los na sua aprendizagem. Por vezes, até elaboram provas para "reprovar" seus alunos. Uma situação que exemplifica esse ato irrefletido ocorreu numa escola pública municipal de Silva Jardim, quando se deu um diálogo entre professores, dos quais 2 profissionais fizeram uma prova do tipo A, B e C para fazer uma pegadinha com os alunos. Na realidade, segundo estes professores, tratava-se de um "método"3 para ver quem realmente "estudou" para a prova. Destas, a prova C era a mais difícil. A conseqüência foi facilmente prevista. Os alunos tiraram notas inferiores ao mínimo estabelecido. Me pergunto até que ponto essa atitude seria válida? Será que uma "pegadinha" poderia ser considerada como uma avaliação? Se uma avaliação escrita já adquiriu o status de "método", que tipo de "método" seria?

\footnotetext{
${ }^{2}$ Muitas vezes o conhecimento científico é trabalhado de forma demasiadamente detalhada e o processo de transposição didática tende a ser quase imperceptível. O objetivo de uma prova escrita nas disciplinas de ciências parece ser o de preparar os aluno para a vida acadêmica científica, isto é, como se os alunos fossem cientistas em miniatura.

${ }^{3}$ As palavras "método" e "estudou" são colocados entre aspas para realçar os termos que fizeram parte da discussão dos professores.
} 
A avaliação não é um método, mas sim um procedimento utilizado no âmbito escolar para diagnosticar o rendimento individual e grupal dos alunos e, consequentemente, da escola. $\mathrm{O}$ que existem são muitos métodos, muitas formas de avaliar, dentre as quais a avaliação escrita faz parte, sendo um dos mais antigos instrumentos avaliativos.

Luckesi (1996:21) deixa claro que esse mal uso das tecnologias avaliativas são responsáveis por muitos problemas educacionais. Com a mesma linha de pensamento, Caetano (p. 95) considera que a fé nos instrumentos de avaliação revela imagens da importância do rigor, e muitos professores obedecem a essa tradição preparando provas "bem elaboradas"4, sem perceber que em sua maioria só verificam o que o aluno não sabe. Que relevância tem esse propósito de produzir uma prova elaborada, mais difícil? Por que questões com um nível de complexidade maior do que aquele que o aluno é capaz de realizar? Qual o prazer de permitir ao aluno errar?

Nesse sentido, o que será que os professores querem afinal com a prova escrita? Os seus objetivos nem sempre convergem com os objetivos planejados no início do ano letivo (descritos no plano de curso inclusive) e com a abordagem realizada no decorrer das aulas dos conteúdos de ciências. Quais os objetivos do professor quando ele cria ou coleta de outros materiais as questões de suas provas?

Apoiando-se nas idéias de Delizoicov, Angotti e Pernambuco (2002), estes defendem em relação à aplicação do conhecimento científico:

“ (...) independente do emprego do aparato matemático disponível para enfrentar essa classe de problemas, a identificação e o emprego da conceituação envolvida - ou seja, o suporte teórico fornecido pela ciência - é que estão em pauta nesse momento. É um uso articulado da estrutura do conhecimento científico com as situações significativas, envolvidas nos temas, para melhor entendê-las, uma vez que essa é uma das metas a ser atingidas com o ensino-aprendizagem das ciências. É o potencial explicativo e conscientizador das teorias científicas que precisa ser explorado."

Podemos traçar um paralelo e relacionar a importância da avaliação escrita com esse momento de aplicação do conhecimento construído. É um conhecimento que deveria ser articulado de acordo com o que o aluno aprendeu e leva consigo. A prova escrita deveria ser planejada pelo professor para, ainda neste momento de avaliação, desenvolver a aprendizagem através de uma expressão escrita, e não uma forma de prejudicar o aluno. Não trata-se de um sadismo escolar científico, mas sim de uma avaliação de conhecimentos importantes para a compreensão do ambiente em que vive e que o aluno construiu de alguma forma, por mais que não esteja tão próxima do modelo científico mais aceito. $O$ trecho se resume quando os autores dizem que é o potencial explicativo e conscientizador das teorias científicas que precisa ser explorado. O que é preciso obter do aluno para a realização de uma avaliação escrita é justamente fazer com que o mesmo utilize-se de seu potencial explicativo e que conscientize-se da necessidade de aplicar o conhecimento dos conteúdos para solucionar de forma crítica e lógica ${ }^{5}$ um determinado problema numa situação específica. Isso não se torna tão difícil se preparamos uma prova que avalie de forma positiva o alunado, ou seja, que possa recolher todas as informações necessárias e que permita um trabalho posterior dos conteúdos que não ficaram tão claro para a turma. Dessa forma teríamos uma vantajosa avaliação escrita capaz de avaliar a verdadeira compreensão do conhecimento científico que o aluno adquiriu.

\footnotetext{
${ }^{4}$ A expressão "bem elaborada" corresponde ao que comumente muitos professores chamariam de "provas difíceis", "pegadinhas", "é o bicho", etc.

${ }^{5} \mathrm{~A}$ forma crítica e lógica se caracteriza pela atitude participativa e julgadora diante das situações propostas nas avaliações e lógicas quando se refere ao raciocínio e aplicação do conhecimento adquirido para resolução dos problemas propostos.
} 
A modificação na forma de compor as avaliações escritas poderia gradativamente cortar a corda que liga o tradicionalismo enciclopédico às expressões escritas. Rubem Alves relaciona as avaliações com a permanência de um jogo de poder em sala de aula. O filósofo e educador faz uma crítica quando diz que os professores deveriam parar para pensar no jogo que obrigam seus alunos a jogar. Uma das características desse jogo é que o aluno é obrigado a aceitar as "entidades" com que deve jogar. (2003:95). A avaliação escrita faz parte do jogo em que o professor é quem comanda e/ou a realiza como este deseja, através das questões que o mestre do jogo seleciona e que não são passíveis de qualquer crítica. $O$ bom aluno saberá responder a todas as questões e o mau, contará seus décimos, contando com a sorte para atingir o limite mínimo para ser aprovado (p. 95).

Partindo desses pressupostos, torna-se então interessante refletirmos em nossa prática docente e em na forma como produzimos as avaliações. Como são produzidas nossas avaliações em áreas do conhecimento tão dinâmicas e interativas quanto às ciências. Será que as avaliações também não poderiam ser um momento de aprendizagem? Podemos refletir em até que ponto essas provas podem contribuir verdadeiramente para o ensino-aprendizado de ciências, propondo métodos e criticando os meios que aparentemente não resultam num bom rendimento escolar, mas também considerando todos os fatores externos influentes ${ }^{6}$ contribuindo de alguma forma para a melhoria da compreensão das ciências no ensino básico do país.

\section{BIBLIOGRAFIA SUGERIDA}

ALVES, R. Entre a ciência e a sapiência. O dilema da educação. $10^{a}$ Edição. Edições Loyola. 2003. São Paulo, SP. 148 pp.

ANTUNES, C. A Avaliação da Aprendizagem Escolar. $3^{\text {a }}$ Edição. Editora Vozes. 2003. Petrópolis, RJ.

Caetano, J. J. A Percepção e a Interpretação nas Avaliações escritas de Matemática. Departamento de Ciências Exatas.19_.Unicentro, Irati, PR

ChevallaRd, Y. La transposición Didáctica: Del saber sábio al saber enseñado. Aique. 1991. Argentina.

Delizolcov, D. Angotti, J. A. Pernambuco, M. M. Ensino de Ciências: Fundamentos e Métodos. Editora Cortez. 2002. São Paulo, SP. 365 pp.

GIL, A .C. Métodos e Técnicas de Pesquisa Social. Editora Atlas. 1999. São Paulo, SP.

LUCKESI, C. C. Avaliação da Aprendizagem Escolar. $3^{a}$ Edição. Editora Cortez. 1996. São Paulo, SP. 1996. $180 \mathrm{pp}$.

Mansur, O . M .F. de C. Moretto, R. Aprendendo a ensinar. Editora Elevação. 2000. São Paulo, SP.

\footnotetext{
${ }^{6}$ tais como motivação, conhecimento das condições sócio-econômicas dos alunos, condições da escola e de permanência dos alunos na escola, etc.
} 


\title{
Contactar
}

Revista lberoamericana de Educación

\author{
Principal OEI
}

